\title{
Intraosseous Radiofrequency Ablation of the Basivertebral Nerve in Chronic Low Back Pain: A Meta-Analysis
}

\author{
Alistair J. Loan', David C. Kieser ${ }^{2 *}$ \\ ${ }^{1}$ Radiology Department, Canterbury District Health Board, Christchurch, New Zealand \\ ${ }^{2}$ Department of Orthopaedic Surgery and Musculoskeletal Medicine, University of Otago, Christchurch, New Zealand \\ Email: *kieserdavid@gmail.com
}

How to cite this paper: Loan, A.J. and Kieser, D.C. (2021) Intraosseous Radiofrequency Ablation of the Basivertebral Nerve in Chronic Low Back Pain: A Meta-Analysis. Open Journal of Radiology, 11, 81-90. https://doi.org/10.4236/ojrad.2021.113008

Received: July 7, 2021

Accepted: August 10, 2021

Published: August 13, 2021

Copyright $\odot 2021$ by author(s) and Scientific Research Publishing Inc. This work is licensed under the Creative Commons Attribution International License (CC BY 4.0).

http://creativecommons.org/licenses/by/4.0/

(c) (i) Open Access

\begin{abstract}
Purpose: To review the literature on the value of basivertebral nerve ablation in the treatment of chronic low back pain. Materials and Method: A systematic review and meta-analysis of the English literature to March 2020 was undertaken. The inclusion criteria were patients with discogenic back pain of more than 3 months duration with modic type 1 or 2 change and successful disc block or discogram. Primary outcomes were VAS pain, ODI, EQ-5D and SF36 improvement. Secondary outcomes were complications. Results: 6 studies were included, all funded by the same company, but otherwise of low bias. All studies showed significant improvement in all scores over the first 3 months with evidence these would be maintained over the longer term. There was one reported compression fracture, but otherwise no significant adverse events. Conclusion: This study supports the conclusion that radiofrequency ablation of the basivertebral nerve is a safe and effective treatment for discogenic chronic low back pain.
\end{abstract}

\section{Keywords}

Basivertebral Nerve, Radiofrequency Ablation, Chronic Back Pain, Discogenic Back Pain, Modic Type Changes

\section{Introduction}

Low back pain is a major health problem worldwide with estimations of a lifetime prevalence of over $80 \%$ [1]. It has the highest burden of years lived with disability out of all musculoskeletal conditions worldwide [2]. In the United States, low back pain is the second most prevalent cause of disability with an estimated $30 \%$ of adults in the United States having experienced low back pain in 
the past 3 months [3] [4].

Fortunately, the majority of people with low back pain recover. For those who do not, they can experience a slow recovery with multiple relapses, placing a high burden on the health system [5] [6]. Over recent years, and particularly in the western world, there has been a rising prevalence of chronic low back pain, now estimated to affect up to $10 \%$ of the population in USA [6] [7]. Treatment of chronic low back pain is variable including conservative, complementary and surgical options [8]. The cost of low back pain, not only in treatment but also in burden to society, is substantial, thought to exceed $\$ 100$ billion in the United States, though it is difficult to measure the true overall cost [9] [10].

Low back pain can be caused by a wide range of aetiologies including degenerative, inflammatory, infective, neoplastic, referred, psychogenic, trauma and congenital causes [11]. Disc degeneration and associated endplate changes have been associated with low back pain and have been the target of treatments over the years [12]. Traditionally treatment begins with non-surgical options before moving onto surgical options with variable success [13] [14] [15]. Recent research has suggested the endplate becomes highly sensitised secondary to disc degeneration with growth of nerves into the adjacent disc [16] [17] [18] [19].

The presence of the basivertebral nerve was first definitively described in humans in 1998 [16]. The nerves were found to enter the vertebral body posteriorly through the vascular foramen, accompanying the basivertebral vessels, before branching centrally and peripherally in the vertebral bodies. They contain substance $\mathrm{P}$, a peptide neurotransmitter released in response to nociceptive stimuli [20]. This strongly suggests the potential for these nerves to transmit pain signals from the vertebral bodies and vertebral body endplates thus providing a potential new target for treatment of low back pain.

The basivertebral nerve was successfully ablated by radiofrequency in multiple ovine models raising the possibility of similar treatment in humans [21]. In humans, the procedure can be carried out through a transpedicular or extrapedicular unilateral approach targetting the vertebral body endplate above and below the affected disc level. An introducer cannular is advanced through the posterior wall of the vertebral body. The trocar is removed and exchanged for a curved cannula to create a channel to the predetermined position of the trunk of the basivertebral nerve near the centre of the vertebral body. Finally a radiofrequency probe is passed through the cannula and activated create a $1 \mathrm{~cm}$ spherical lesion within the vertebral body $\left(85^{\circ} \mathrm{C}\right.$ for $\left.15 \mathrm{~min}\right)$ [22] [23] [24] [25].

This procedure has been assessed in multiple published trials over the past few years with positive outcomes, however the data has not been collated to fully assess the efficacy of this treatment in chronic low back pain.

In this study, we aim to review the literature to provide a more complete assessment of the efficacy of basivertebral nerve ablation in patients suffering from chronic low back pain based on changes in patient reported pain and function at regular intervals up to 2 years post-procedure. 


\section{Method}

A systematic search was conducted involving identification of studies, screening for validity, extraction and analysis of data, inferences and finally presentation of results.

\subsection{Search Methods}

The following computerised databases were searched: Medline via Ovid, Cochrane Library, Google scholar, EmBase via Ovid, and Pubmed. The search terms included a combination of "basivertebral nerve", "ablation", "chronic", and "low back pain". Any studies published before March 2020 were included.

\subsection{Study Selection}

Study types included randomised controlled trials, case-control studies and observational cohort studies. Inclusion criteria were chronic discogenic back pain for more than 3 months duration, and flexural pain with; modic type 1 or 2 change, successful disc block, or positive discography.

Exclusions were commentaries, reviews or conference proceedings, age $<18$ years, radicular pain, spinal stenosis, instability/spondylolisthesis, previous spinal surgery, revision basivertebral nerve ablation, ankylosing spinal conditions, and spinal neoplasm.

Treatment was with basivertebral nerve ablation either transpedicular or extrapedicular. In addition, when articles presented the same data set, the most thorough article was included and the remainder excluded.

Outcomes assessed were clinically proven pain, mobility and function scores as well as any complications, including but not limited to infection, subsequent surgery for back pain, and spinal nerve damage.

\subsection{Validity Assessment}

Included studies were independently assessed by two reviewers for inclusion and duplication, initially with abstract screening then by full text screening. Any conflicts in assessment were discussed and papers subsequently included or excluded by consensus agreement.

\subsection{Data Extraction and Analysis}

Data from each paper was then extracted to a combined table for statistical analysis and interpretation. The data was assessed for changes in scores, using the baseline as a comparision. Where controls were available these scores were also used.

Risk of bias was assessed using the updated ROBINS-I tool [26].

\section{Results}

Figure 1 shows the total studies identified and subsequent exclusions. The search of the databases on basivertebral nerve ablation, as outlined above, 
Records after duplicates removed

$$
(n=42)
$$

مْ

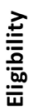

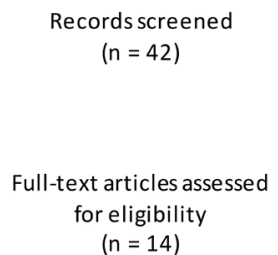

$\frac{\text { 윰 }}{\text { 음 }}$

Studies included in quantitative synthesis (meta-analysis) ( $\mathrm{n}=6$ ) qualitative synthesis $(n=7)$

Studies included in
Additional records identified

through other sources
Records excluded

$(n=28)$

Figure 1. PRISMA chart.

yielded 42 studies. Abstract screening identified 14 potentially relevant studies. A further 7 studies were subsequently excluded following assessment of the full text due to duplication of patient cohort or inappropriate study/paper design. One study was assessed from two separate articles to complete the data set. The first had a comparison group and follow up for 1 year, while the other had no comparison group but follow up for 2 years [24] [27]. A total of 6 individual studies were included in the final assessment [23] [24] [27] [28] [29] [30] [31].

There were 2 studies with randomised control groups. Fischgrund et al. compared 147 treatment arm patients with 78 sham operation patients over 12 month follow up at which point patients in the sham arm were allowed to transfer to the treatment arm [24]. Khalil et al. compared 51 treatment arm patients with 53 standard care patients with follow up planned for regular intervals over 12 months [28]. The remaining 4 studies were prospective observational cohort studies [23] [29] [30] [31]. In total there were 267 patients treated with basivertebral nerve ablation. All papers reported outcomes in the Oswestry Disability Index (ODI), and the Visual Analogue Scale (VAS). Four reported SF-36 PCS, three SF-36 MCS. Finally two reported EQ-5D-5L outcomes. There were no serious adverse events reported.

The patients in the studies all had similar demographics with a relatively even mix of gender, an average age of $46-50$ years and body mass index of $27-28$ $\mathrm{kg} / \mathrm{m}^{2}$.

Table 1 shows the mean estimated changes in ODI, VAS, EQ 5d and SF 36 at 
various time intervals.

Figure 2 shows the changes in ODI from each paper at each time interval. The mean changes in score of ODI were a 33.2 point improvement at 1 - 2 weeks, although only 3 studies reported outcomes this early. Improvements of 27.5 at three months and 35.9 at six months were also seen. Fischgrund et al. reported outcomes at 12 and 24 months of 19.8 and 23.4 respectively [24] [27].

Figure 3 shows changes in VAS from each paper at each time interval. VAS assessments showed a similar magnitude improvement as ODI with pooled estimate change of 4.3 at $1-2$ weeks, 3.4 at 3 months and 4.5 at 6 months. Again, sustained improvement was confirmed by Fischgrund et al. with improvement of 2.8 at 12 months and 3.6 at 24 months [24] [27].

Figure 4 shows the changes in scores in quality of life scores from each paper at 3 months. QOL score assessments were significantly improved at three months. SF36-PCS showed improvement of 11.8 at 3 months which was sustained at 6,12 and 24 months. EQ-5D-5L showed improvement of 0.18 at 3 months.

One patient, on high dose steroid for a gender reassignment, was recorded to experience a compression fracture.

Table 2 shows the results from the ROBINS-I assessment of bias. This shows that there is a low risk of bias overall from all the included studies. However, it should be noted that all studies were funded by the same company.

ODI change 1-2 Weeks

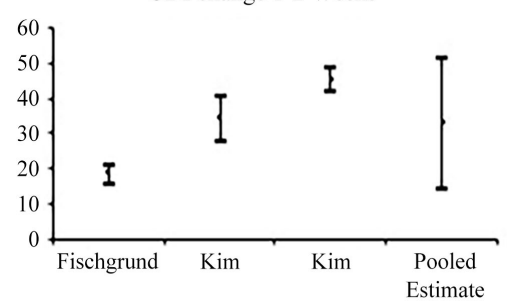

ODI change 3 months

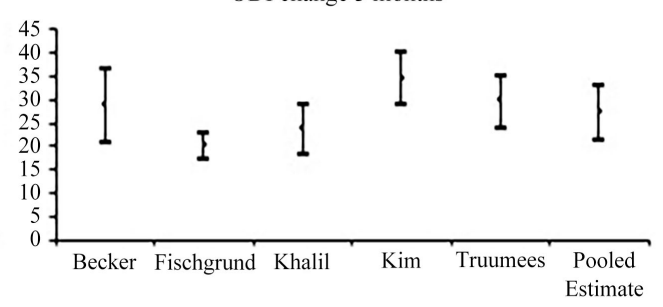

ODI change 6 months

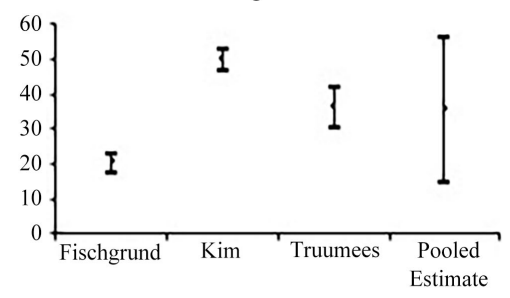

Figure 2. ODI changes.

VAS change 1-2 Weeks

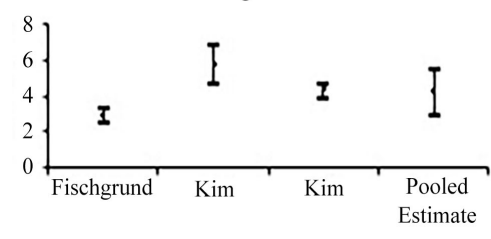

VAS change 3 months

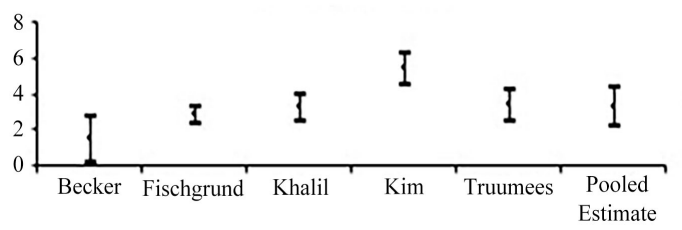

VAS change 6 months

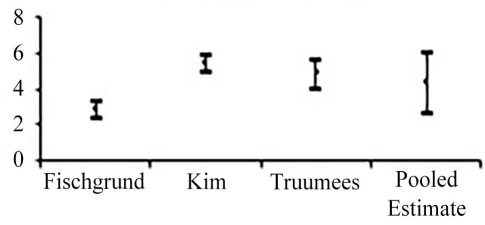

Figure 3. VAS pain change.
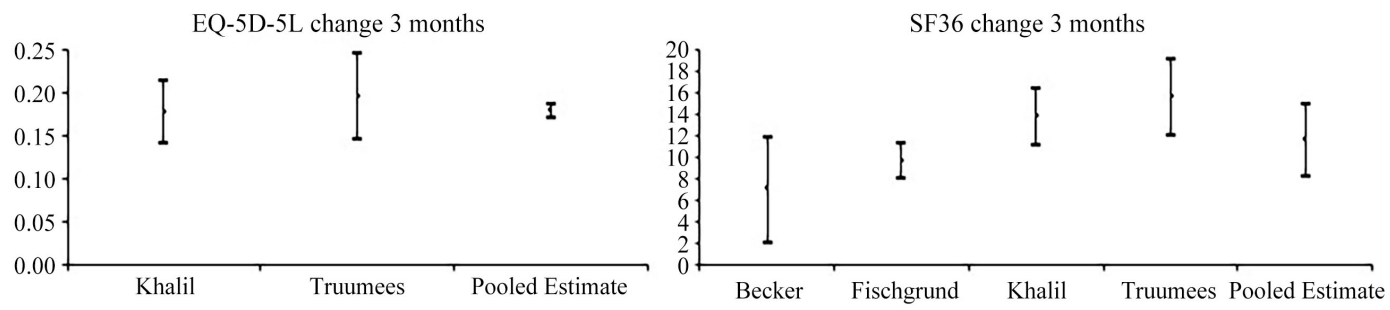

Figure 4. EQ-5D-5L and SF36 change at 3 months. 
Table 1. Changes in ODI, VAS, EQ 5d and SF 36 at various time intervals.

\begin{tabular}{ccccc}
\hline \multicolumn{2}{c}{ Changes in scores } & & & \\
\hline & ODI & VAS & EQ 5D 5L & SF 36 \\
\hline $1-2$ weeks & 33.1866 & 4.3337 & 0.1816 & 11.8484 \\
3 months & 27.4728 & 3.4208 & & \\
6 months & 35.9348 & 4.4705 & & \\
\hline
\end{tabular}

Table 2. ROBINS-I assessment for bias.

\begin{tabular}{ccccccccc}
\hline Author & Confounding & Selection & Classification & Intended intervention & Missing data & Outcome & Report & Overall \\
\hline Becker et al. [23] & Low & Low & Low & Low & Low & Low & Low & Low \\
Fischgrund et al. [24] & Low & Low & Low & Low & Low & Low & Low & Low \\
Khalil et al. [28] & Low & Low & Low & Low & Low & Low & Low & Low \\
Kim et al. [29] & Low & Low & Low & Low & Low & Low & Low & Low \\
Kim et al. [30] & Low & Low & Low & Low & Low & Low & Low & Low \\
Truumees et al. [31] & Low & Low & Low & Low & Low & Low & Low & Low \\
\hline
\end{tabular}

\section{Discussion}

This systematic review was carried out to allow an overall assessment of the efficacy of basivertebral nerve ablation in treating chronic low back pain. Six studies have been published on this subject which were included in this review. Additional pilot studies were not included as they did not meet criteria for peer reviewed papers.

Many of the studies used baseline measurements as a comparison to assess the outcomes. Additionally two of the larger studies also contained a control group. Fischgrund et al. performed a sham operation on the control group with blinded follow up [24]. The control group was allowed to cross over after 12 months. Further follow up from 12 months was performed using baseline for comparison. Khalil et al. had a control arm which received the standard treatment as advised by their clinician [28]. An interim analysis was planned for when $60 \%$ of participants had reached 3 months of follow up, which was then reviewed by an independent Data Management Committee (DMC). At this point, the RF ablation arm showed statistical superiority and the DMC recommended the study be halted and that patients in the standard care arm be offered early cross-over to the RF ablation arm.

The main patient reported outcome measure for most studies was ODI. This requires a 10 point improvement to demonstrate a minimal clinically important difference (MCID) [32]. All studies reported improvements of 2 - 3 times this level. These changes appear to be sustained over a long period of time, with follow up out to 2 years at this stage.

VAS outcomes were also collected for all studies. It requires a 1.8 - 1.9 unit improvement for MCID [32]. Once again, outcomes across all studies were 2 - 3 times better than this and sustained over 2 years.

Fewer studies collected information on SF-36 which showed an improvement 
of twice the MCID at 3 months [33]. EQ-5D-5L is a relatively recently developed outcome tool which can be used as a measure of health related quality of life [34]. Values in the tool range from perfect health scoring 1 to death scoring 0. Health state regarded as worse than death score $<0$. RF ablation of the basivertebral nerve produced a 0.18 improvement. MCID for chronic low back pain has not yet been established.

There were no serious adverse events reported directly related to ablation of the basivertebral nerve throughout all the included studies. There were some mild adverse events such as incisional pain, urinary retention and transient neuropraxia were recorded. Some of these were considered general procedural related. These all resolved over a short period of time with minimal treatment required.

The cost-effectiveness of this novel treatment has not yet been performed. This would require increased patient numbers and longer term follow up to fully assess this.

This systematic review has a number of limitations that need to be considered when interpreting the results. Firstly, it is limited by the relatively small number of papers available and that all of these papers were funded by the same company. Secondly, it is limited by the follow up in many of the included papers, some only extending out to 3 months. Thirdly, the included studies used an intention to treat analysis, yet post-procedural MRI has shown high basivertebral nerve ablation miss rates. Further research on this is required.

\section{Conclusion}

In conclusion, radiofrequency ablation of the basivertebral nerve in the treatment of chronic low back pain is safe and may be helpful in a carefully selected group of patients with demonstrable Modic type changes, with improvements in patient outcomes achieving $2-3$ times the minimal clinically important difference. Further independent research would help to clarify the cost-effectiveness, efficacy and longer-term outcome of this procedure.

\section{Acknowledgements}

Glynny Kieser for her editorial input.

\section{Conflicts of Interest}

The authors declare no conflicts of interest regarding the publication of this paper.

\section{References}

[1] Balagué, F., Mannion, A.F., Pellisé, F. and Cedraschi, C. (2012) Non-Specific Low Back Pain. The Lancet, 379, 482-491. https://doi.org/10.1016/S0140-6736(11)60610-7

[2] Vos, T., Flaxman, A.D., Naghavi, M., Lozano, R., Michaud, C., Ezzati, M., et al. (2012) Years Lived with Disability (YLDs) for 1160 Sequelae of 289 Diseases and 
Injuries 1990-2010: A Systematic Analysis for the Global Burden of Disease Study 2010. The Lancet, 380, 2163-2196. https://doi.org/10.1016/S0140-6736(12)61729-2

[3] Centers for Disease Control and Prevention (CDC) (2001) Prevalence of Disabilities and Associated Health Conditions among Adults-United States, 1999. MMWR Morbidity and Mortality Weekly Report, 50, 120-125.

[4] Centers for Disease Control and Prevention (CDC) (2020) Percentage of Adults Aged $\geq 18$ Years Who Had Lower Back Pain in the Past 3 Months, by Sex and Age Group-National Health Interview Survey, United States, 2018. Morbidity and Mortality Weekly Report, 68, Article No. 1196.

https://www.cdc.gov/mmwr/volumes/68/wr/mm685152a5.htm https://doi.org/10.15585/mmwr.mm685152a5

[5] Hoy, D., Brooks, P., Blyth, F. and Buchbinder, R. (2010) The Epidemiology of Low Back Pain. Best Practice \& Research Clinical Rheumatology, 24, 769-781.

https://doi.org/10.1016/j.berh.2010.10.002

[6] Andersson, G.B. (1999) Epidemiological Features of Chronic Low-Back Pain. The Lancet, 354, 581-585. https://doi.org/10.1016/S0140-6736(99)01312-4

[7] Freburger, J.K., Holmes, G.M., Agans, R.P., Jackman, A.M., Darter, J.D., Wallace, A.S., et al. (2009) The Rising Prevalence of Chronic Low Back Pain. Archives of Internal Medicine, 169, 251-128. https://doi.org/10.1001/archinternmed.2008.543

[8] Koes, B.W., van Tulder, M.W. and Thomas, S. (2006) Diagnosis and Treatment of Low Back Pain. BMJ, 332, 1430-1434. https://doi.org/10.1136/bmj.332.7555.1430

[9] Katz, J.N. (2006) Lumbar Disc Disorders and Low-Back Pain: Socioeconomic Factors and Consequences. The Journal of Bone \& Joint Surgery, 88, 21-24. https://doi.org/10.2106/00004623-200604002-00005

[10] Dagenais, S., Caro, J. and Haldeman, S. (2008) A Systematic Review of Low Back Pain Cost of Illness Studies in the United States and Internationally. The Spine Journal, 8, 8-20. https://doi.org/10.1016/j.spinee.2007.10.005

[11] Krismer, M. and van Tulder, M. (2007) Low Back Pain (Non-Specific). Best Practice \& Research Clinical Rheumatology, 21, 77-91. https://doi.org/10.1016/j.berh.2006.08.004

[12] Luoma, K., Riihimäki, H., Luukkonen, R., Raininko, R., Viikari-Juntura, E. and Lamminen, A. (2000) Low Back Pain in Relation to Lumbar Disc Degeneration. Spine, 25, 487-492. https://doi.org/10.1097/00007632-200002150-00016

[13] Sidhu, K.S. and Herkowitz, H.N. (1997) Spinal Instrumentation in the Management of Degenerative Disorders of the Lumbar Spine. Clinical Orthopaedics and Related Research, 335, 39-53. https://doi.org/10.1097/00003086-199702000-00005

[14] Herkowitz, H.N. and Sidhu, K.S. (1995) Lumbar Spine Fusion in the Treatment of Degenerative Conditions: Current Indications and Recommendations. Journal of the American Academy of Orthopaedic Surgeons, 3, 123-135. https://doi.org/10.5435/00124635-199505000-00002

[15] Ibrahim, T., Tleyjeh, I.M. and Gabbar, O. (2008) Surgical versus Non-Surgical Treatment of Chronic Low Back Pain: A Meta-Analysis of Randomised Trials. International Orthopaedics, 32, 107-113. https://doi.org/10.1007/s00264-006-0269-6

[16] Darryl, A.M., Mody, D.R. and Heggeness, M.H. (1998) Innervation of the Human Vertebral Body: A Histologic Study. Journal of Spinal Disorders, 11, 526-531. https://doi.org/10.1097/00002517-199812000-00013

[17] Palmgren, T., Grönblad, M., Virri, J., Seitsalo, S., Ruuskanen, M. and Karaharju, E. (1996) Immunohistochemical Demonstration of Sensory and Autonomic Nerve 
Terminals in Herniated Lumbar Disc Tissue. Spine, 21, 1301-1306. https://doi.org/10.1097/00007632-199606010-00004

[18] Freemont, A., Peacock, T., Goupille, P., Hoyland, J., O’Brien, J. and Jayson, M. (1997) Nerve Ingrowth into Diseased Intervertebral Disc in Chronic Back Pain. The Lancet, 350, 178-181. https://doi.org/10.1016/S0140-6736(97)02135-1

[19] Freemont, A.J., Watkins, A., Maitre, C.L., Baird, P., Jeziorska, M., Knight, M.T.N., et al. (2002) Nerve Growth Factor Expression and Innervation of the Painful Intervertebral Disc. The Journal of Pathology, 197, 286-292.

https://doi.org/10.1002/path.1108

[20] Fras, C., Kravetz, P., Mody, D.R. and Heggeness, M.H. (2003) Substance P-Containing Nerves within the Human Vertebral Body: An Immunohistochemical Study of the Basivertebral Nerve. The Spine Journal, 3, 63-67.

https://doi.org/10.1016/S1529-9430(02)00455-2

[21] Jack Hoopes, D., Eskey, C.J., Attawia, M., Patel, S.J., Ryan, T.P., Pellegrino, R., et al. (2005) Radiofrequency Ablation of the Basivertebral Nerve as Potential Treatment of Back Pain: Pathologic Assessment in an Ovine Model. In: Thermal Treatment of Tissue: Energy Delivery and Assessment III, International Society for Optics and Photonics, Bellingham, 168-180. https://doi.org/10.1117/12.593693

https://www.spiedigitallibrary.org/conference-proceedings-of-spie/5698/0000/Radio frequen-

cy-ablation-of-the-basivertebral-nerve-as-potential-treatment-of/10.1117/12.593693 short

[22] Heggeness, M., Becker, S., Hadjipavlou, A., Danielson, G., Calodney, A., Belza, M., et al. (2011) Ablation of the Basivertebral Nerve for the Treatment of Back Pain: A Pilot Clinical Study. The Spine Journal, 11, 65-66.

https://doi.org/10.1016/j.spinee.2011.08.166

[23] Becker, S., Hadjipavlou, A. and Heggeness, M.H. (2017) Ablation of the Basivertebral Nerve for Treatment of Back Pain: A Clinical Study. The Spine Journal, 17, 218-223. https://doi.org/10.1016/j.spinee.2016.08.032

[24] Fischgrund, J.S., Rhyne, A., Franke, J., Sasso, R., Kitchel, S., Bae, H., et al. (2018) Intraosseous Basivertebral Nerve Ablation for the Treatment of Chronic Low Back Pain: A Prospective Randomized Double-Blind Sham-Controlled Multi-Center Study. European Spine Journal, 27, 1146-1156.

https://doi.org/10.1007/s00586-018-5496-1

[25] Relievant (n.d.) The Intracept Procedure for the Relief of Chronic Vertebrogenic Low Back Pain. https://www.relievant.com/intracept-procedure-2/procedure

[26] Sterne, J.A., Hernán, M.A., Reeves, B.C., Savović, J., Berkman, N.D., Viswanathan, M., et al. (2016) ROBINS-I: A Tool for Assessing Risk of Bias in Non-Randomised Studies of Interventions. BMJ, 355, Article No. i4919.

https://www.bmj.com/content/355/bmj.i4919

https://doi.org/10.1136/bmj.i4919

[27] Fischgrund, J.S., Rhyne, A., Franke, J., Sasso, R., Kitchel, S., Bae, H., et al. (2019) Intraosseous Basivertebral Nerve Ablation for the Treatment of Chronic Low Back Pain: 2-Year Results from a Prospective Randomized Double-Blind Sham-Controlled Multicenter Study. International Journal of Spine Surgery, 13, 110-119. https://doi.org/10.14444/6015

[28] Khalil, J.G., Smuck, M., Koreckij, T., Keel, J., Beall, D., Goodman, B., et al. (2019) A Prospective, Randomized, Multicenter study of Intraosseous Basivertebral Nerve Ablation for the Treatment of Chronic Low Back Pain. The Spine Journal, 19, 1620-1632. https://doi.org/10.1016/j.spinee.2019.05.598 
[29] Kim, H.S., Adsul, N., Yudoyono, F., Paudel, B., Kim, K.J., Choi, S.H., et al. (2018) Transforaminal Epiduroscopic Basivertebral Nerve Laser Ablation for Chronic Low Back Pain Associated with Modic Changes: A Preliminary Open-Label Study. Pain Research and Management, 2018, Article ID: 6857983.

https://doi.org/10.1155/2018/6857983

[30] Kim, H.S., Wu, P.H. and Jang, I.-T. (2020) Lumbar Degenerative Disease Part 1: Anatomy and Pathophysiology of Intervertebral Discogenic Pain and Radiofrequency Ablation of Basivertebral and Sinuvertebral Nerve Treatment for Chronic Discogenic Back Pain: A Prospective Case Series and Review of Literature. International Journal of Molecular Sciences, 21, Article No. 1483.

https://doi.org/10.3390/ijms21041483

[31] Truumees, E., Macadaeg, K., Pena, E., Arbuckle, J., Gentile, J., Funk, R., et al. (2019) A Prospective, Open-Label, Single-Arm, Multi-Center Study of Intraosseous Basivertebral Nerve Ablation for the Treatment of Chronic Low Back Pain. European Spine Journal, 28, 1594-1602. https://doi.org/10.1007/s00586-019-05995-2

[32] Hägg, O., Fritzell, P. and Nordwall, A. (2003) The Clinical Importance of Changes in Outcome Scores after Treatment for Chronic Low Back Pain. European Spine Journal, 12, 12-20. https://doi.org/10.1007/s00586-002-0464-0

[33] Copay, A.G., Glassman, S.D., Subach, B.R., Berven, S., Schuler, T.C. and Carreon, L.Y. (2008) Minimum Clinically Important Difference in Lumbar Spine Surgery Patients: A Choice of Methods Using the Oswestry Disability Index, Medical Outcomes Study Questionnaire Short Form 36, and Pain Scales. The Spine Journal, 8, 968-974. https://doi.org/10.1016/j.spinee.2007.11.006

[34] Payakachat, N., Ali, M.M. and Tilford, J.M. (2015) Can the EQ-5D Detect Meaningful Change? A Systematic Review. PharmacoEconomics, 33, 1137-1154. https://doi.org/10.1007/s40273-015-0295-6 